\title{
Políticas curriculares e formação de professores no Brasil: a disputa em torno do conceito de competências
}

\section{Curriculum Policies and Teacher Education in Brazil: The Dispute on the Concept of Skills}

\section{Políticas curriculares y formación de profesores en Brasil: la disputa alrededor del concepto de habilidades}

\section{Silvana Malheiro ${ }^{1}$ y Jorge Najjar ${ }^{2}$}

Fecha de recepción: 25/06/2018

Fecha de evaluación: 20/07/2018

Fecha de aceptación: 30/07/2018

Disponible en línea:

DOI: https://doi.org/10.18359/reds.4359

Cómo citar este artículo:

Malheiro, S y Najjar, J. (2018). Políticas curriculares e formação de professores no Brasil: a disputa em torno do conceito de competências. Revista Educación y Desarrollo Social, 12(2), 53-74.

Doutoranda em Educação pela Universidade Federal Fluminense - UFF / Brasil. Pedagoga da 


\section{Resumen}

Las reformas educativas brasileras de los años 1990 presentaron el concepto de competencias como nuclear en la organización curricular, estando este concepto presente en los principales documentos curriculares para la formación de profesores a nivel nacional. En ese período, entre finales de la década de 1990 e inicios de los años 2000, fue predominante el discurso que pretendía construir la calidad de la formación del docente, y en este discurso el concepto de competencias era central. Sin embargo, tal discurso pierde fuerza en los documentos curriculares aún al final de la primera década de los años 2000. La tónica del discurso se vuelve en torno a la afirmación de una base común nacional para la formación inicial y continuada y en la articulación entre el Sistema Nacional de Educación, las políticas y la valorización de los profesionales de la educación. Este artículo busca analizar el proceso de disputa de las políticas que giraron en torno a la efectividad de la idea de competencias como núcleo central de los textos curriculares, así como de los procesos de disputa por su negación. Aunque presenta una discusión específica de cómo estas disputas sucedieron en Brasil, él lanza luces para procesos relativamente semejantes que ocurrieron en Colombia y en otros países de América del Sur.

Palabras clave: formación de profesores; habilidades; políticas curriculares.

\section{Abstract}

The 1990s Brazilian educational reforms introduced competences as a core concept in curricular organization, integrating this concept in curriculum documents used for teacher education at the national level. In fact, building quality in teacher education was a predominant discourse during the late 1990s and early 2000s, and the concept of competences was a pivotal part of this rhetoric. However, such discourse has lost strength in curricular documents at the end of the first decade of the 2000s, with the rhetoric now revolving around the consolidation of a common national foundation for initial and continuous education, and on the link between the National Education System, different government policies, and the performance evaluation of education professionals. This article seeks to assess the policy discussion processes that revolved around the effectiveness of proposing competences as a core component in curriculum texts as well as the discussion process for their rejection. Although the author specifically addresses the way in which these discussions were developed in Brazil, the article sheds light on relatively similar processes, which also occurred in Colombia and other South American countries.

Palabras clave: formación de profesores; habilidades; políticas curriculares.

\section{Resumo}

As reformas educacionais brasileiras dos anos 1990 apresentaram o conceito de competências como nuclear na organização curricular, estando este conceito presente nos principais documentos curriculares para a formação de professores em âmbito nacional. Nesse período, entre fins da década de 1990 e início dos anos 2000 , foi predominante o discurso que objetivava construir a qualidade da formação docente, e neste discurso o conceito de competências era central. No entanto, tal discurso perde força nos documentos curriculares ainda no fim da primeira década dos anos 2000. A tônica do discurso passa a girar em torno da afirmação de uma base comum nacional para a formação inicial e continuada e na articulação entre Sistema Nacional de Educação, as políticas e a valorização dos profissionais da educação. Este artigo busca analisar o processo de disputa das políticas que giraram em torno da efetivação da ideia de competências como núcleo central dos textos curriculares, bem como dos processos de disputa pela sua negação. Embora apresente uma discussão específica de como estas disputas ocorreram no Brasil, ele lança luzes para processos relativamente semelhantes que ocorreram na Colômbia e em outros países da América do Sul.

Palavras-chave: políticas curriculares; formação de professores; competências. 
Os anos 1990 presenciam o auge da definição de políticas educacionais marcadas por intervenções centralizadas na formação de professores, não só no Brasil, mas no mundo (Ball, 1994), sendo que também os anos 2000 têm sido palco de definição dessas políticas. Nessas intervenções, as políticas curriculares receberam especial atenção, buscando a regulação e normatização dos cursos de formação dos profissionais do magistério.

No Brasil, as reformas educacionais dos anos 1990 apresentaram o conceito de competências como nuclear na organização curricular, estando este conceito presente nos principais documentos curriculares para a formação de professores em âmbito nacional. Nesse período, entre fins da década de 1990 e início dos anos 2000 , foi predominante o discurso que objetivava construir a qualidade da formação docente, e neste discurso o conceito de competências foi definido como a "capacidade de mobilizar múltiplos recursos, entre os quais os conhecimentos teóricos e experienciais da vida profissional e pessoal, para responder às diferentes demandas das situações de trabalho" (Brasil, 1999, p. 61).

No entanto, é possível identificar que o discurso que legitima as competências como central na formação de professores perde força nos documentos curriculares ainda no fim da primeira década dos anos 2000. A tônica do discurso passa a girar em torno da afirmação de uma base comum nacional para a formação inicial e continuada e na articulação entre o Sistema Nacional de Educação, as políticas e a valorização dos profissionais da educação.

Este artigo busca analisar o processo de disputa das políticas que giraram em torno da efetivação da ideia de competências como núcleo central dos textos curriculares, bem como dos processos de disputa pela sua negação. Embora apresente uma discussão específica de como estas disputas ocorreram no Brasil, ele lança luzes para processos relativamente semelhantes que ocorreram na Colômbia e em outros países da América do Sul.

É preciso esclarecer que, apesar da análise e discussões de documentos materializados através de Pareceres e Resoluções constituírem o corpus desse artigo, reiteramos a defesa de que a política curricular não pode ser entendida apenas na sua materialidade documental. De acordo com Ball $(1994,2001)$, as políticas curriculares são processos de negociação complexos, nos quais contextos como a produção dos dispositivos legais, a produção dos documentos curriculares e a prática docente não podem ser entendidos de forma isolada.

Portanto, refutamos a compreensão da política que prestigia sua dimensão formal, ou seja, a perspectiva na qual a política é encarada como guia para a prática. Sob essa perspectiva, as políticas curriculares são entendidas meramente como diretrizes e definições apresentadas em documentos rubricados por agências executivas e legislativas do Estado. 
Tencionamos empreender investigações que busquem o "entendimento de por que as políticas funcionam da maneira que funcionam" (Lopes; Macedo, 2011, p.236) e procuramos entender a política "de forma processual, envolvendo negociação, contestação e luta, portanto, disputa por hegemonia" (Ibdem).

Três documentos produzidos nos anos 2000 receberão atenção nesse momento: as Diretrizes Curriculares Nacionais para a Formação de Professores da Educação Básica, em nível superior, curso de licenciatura, de graduação plena ${ }^{3}$, as Diretrizes Curriculares Nacionais para o Curso de Graduação em Pedagogia, licenciatura ${ }^{4}$ e as Diretrizes Curriculares Nacionais para a formação inicial e continuada dos profissionais do magistério da educação básica ${ }^{5}$. No entanto, outro documento produzido em 1999 também merecerá atenção, tendo em vista apresentar aspectos que ganharão relevância em alguns documentos produzidos no início dos anos 2000. Tal documento intitula-se Referenciais para Formação de Professores, e apresenta-se como mais uma ferramenta útil no processo de reconstrução da escola brasileira (Brasil, 1999), indicando os sentidos que permearão os discursos presentes nos documentos curriculares na década seguinte.

$56 \quad 4$ Resolução CNE/CP 01/2006.

5 Resolução CNE/CP 2/2015 publicada em Diário Oficial da União, Brasília, 2 de julho de 2015 - Seção 1 - pp. 8-12 e retificada em 3/7/2015, Seção 1, p. 28.

\section{Os Referenciais de 1999}

No texto introdutório do documento Referenciais para Formação de Professores (Brasil, 1999), intitulado "Aos responsáveis pela formação de professores", o então Ministro da Educação, Paulo Renato, declara que a finalidade do documento era a de "[...] provocar e, ao mesmo tempo, orientar transformações nas práticas institucionais e curriculares da formação de professores" (Brasil, 1999, p.5). O documento também se considera provocador de reflexões por parte dos formadores de professores e instrumento a ser

Usado nos âmbitos de gestão do sistema educativo e das instituições formadoras, como subsídio para a tomada de decisões políticas. Com essa perspectiva, o presente referencial assume a importância das discussões em torno da formação de educadores, sem perder de vista a necessária articulação com as demais políticas educacionais (Brasil, 1999, p.15).

Atravessado por um discurso reformador, o documento propõe o modelo de profissionalização fundamentado no modelo de competências, porém, enfatiza que tais competências precisariam estar alinhadas com o plano governamental do país.

O objetivo da formação de professores, de acordo com as concepções contidas nestes Referenciais é a sua profissionalização por meio do desenvolvimento de suas competências de modo a permitir que no cum- 
primento das suas funções estejam contempladas as dimensões para o desenvolvimento do nosso país (Brasil, 1999, p.5).

Além disso, a centralidade dada à profissionalização docente denota certo grau de ineditismo, como se antes disso a formação de professores não fosse uma formação profissional.

Os Referenciais apresentam-se estruturados em cinco partes e um anexo. $\mathrm{Na}$ parte I - O papel profissional dos professores: tendências atuais - o documento apresenta diferentes perfis dos professores, faz um resgate histórico da formação de professores no Brasil e apresenta uma análise da situação da formação de professores entre as décadas de 1980 e 1990, bem como as tendências da formação profissional dos educadores, nos âmbitos da formação inicial e continuada.

Na parte II - Repensando a atuação profissional e a formação de professores - aponta às dimensões da atuação do professor e às bases epistemológicas da proposta. Dentre outros aspectos, ao criticar o modelo em que se baseiam os processos de ensino e aprendizagem formativos de professores, o documento denuncia que o enfoque instrumental das práticas de formação "destinam-se a preparar o professor para ser um aplicador e um técnico, e não um profissional com domínio de sua prática e autonomia para a tomada de decisões" (Brasil, 1999, p.42). Também legitima a concepção de competência profissional como cerne da formação docente, porém esclarece que não defende a instituição de um modelo único de professor competente. Segundo o texto,

O desenvolvimento da competência profissional permite ao professor uma relação de autonomia no trabalho, criando propostas de intervenção pedagógica, lançando mão de recursos e conhecimentos pessoais e disponíveis no contexto, integrando saberes, sensibilidade e intencionalidade para responder a situações reais complexas e diferenciadas (Brasil, 1999, p.62).

A parte III - Uma proposta de formação profissional de professores - apresenta as competências profissionais que se constituem em objetivos gerais da formação de professores e seus desdobramentos em âmbitos de conhecimento profissional, as formas de tratamento metodológico dos conteúdos, a organização curricular e a avaliação.

Na parte IV - Indicações para a organização curricular e de ações de formação de professores - o documento explicita sugestões para a formulação de currículose programas de formação docente. Embora reconheça que a formação inicial do professor seja realizada em nível superior, também admite que, por algum tempo, a formação em ensino médio ainda será uma realidade em muitos lugares do país e, por isso, também apresenta, em separado, "indicações para a formação médio" (Brasil, 1999, p.123) 
Sob o subtítulo Indicações para a organização curricular, o documento indica que o currículo precisa desenvolver as competências profissionais. Além disso, independente da organização curricular, o documento aponta ser necessário respeitar uma sequenciação de conteúdos, sendo que, no início do curso, tais conteúdos devem referir-se à função social da escola, às formas de estruturação do sistema educacional, etc. Durante todo o curso e desde o primeiro ano, deveriam ser trabalhados

conteúdos relativos à intervenção pedagógica, às didáticas, à caracterização dos alunos nas diferentes idades e nos diferentes momentos da escolaridade, às relações entre o ensino e a aprendizagem, às fundamentações psicológicas e filosóficas da educação, à gestão de classe e aos conhecimentos experienciais (Ibdem).

Além disso, previa que o curso de formação deveria oferecer formação básica geral, garantindo conhecimentos essenciais relacionados à educação infantil, ao ensino fundamental, à educação de jovens e adultos e de portadores de necessidades especiais. No último ano, porém, levando-se em consideração às peculiaridades de cada sistema de ensino, o futuro professor faria opção por uma especialização em uma das modalidades da educação.

58 Sob o item Indicações para a formação de professores em nível médio, o documento inicia expondo o que denomina "limitações" encontradas pela formação em ensino médio, a saber, "características da etapa de vida dos alunos dessa fase de escolaridade", geralmente entre 15 e 18 anos, e "características do próprio curso". De acordo com o documento, apenas na idade correspondente ao ensino superior, "o nível de autonomia intelectual e emocional necessário ao exercício responsável das funções de professor será possível para a maior parte das pessoas" (Ibdem, p.127), embora reconheça que fatores socioeconômicos e culturais podem produzir "repertórios experienciais e níveis de maturidade diferenciados" (Ibdem). Sobre as características do próprio curso, as Diretrizes atribuem as limitações ao fator tempo, pois a formação básica é concorrente da formação profissional. Por isso, há a indicação de oferecimento do curso em tempo integral, a exemplo dos Centros de Formação e Aperfeiçoamento do Magistério $^{6}$ (CEFAM).

Na parte V-Desenvolvimento profissional permanente e progressão na Carreira - as Diretrizes estabelecem clara distinção entre "professores iniciantes" e "professores experientes" e incentivam a residência pedagógica, destacando o papel do "professor-formador". É necessário destacar, no entanto, que sob esse item aparece a

$6 \quad$ Criados em 1988, os CEFAMs surgiram como um projeto especial da rede pública da Secretaria de Estado da Educação de São Paulo para formar, em nível médio, professores da educação infantil e dos anos iniciais do ensino fundamental. Nos CEFAMs, os alunos estudam em período integral e recebem bolsas para frequentar as aulas (http://www. educacao.sp.gov.br/central-de-atendimento/ Htmexpl/cefam.htm). 
indicação de avaliação da atuação dos docentes, pautada em "competências diretamente relacionadas ao trabalho dos professores", articulada à formação e à progressão na carreira. De maneira enfática, nessa seção, o documento associa essa articulação à possibilidade de promoção da profissionalização docente, indicando a utilização dos resultados da avaliação da atuação profissional do professor para a progressão da carreira.

Sendo assim, a adoção da meritocracia como política de valorização docente é assumida pelas Diretrizes de 1999 e legitimada como cultura em escala global.

O compromisso de contribuir com o desenvolvimento profissional dos professores evidencia a necessidade de se buscar caminhos de instalação de uma cultura de avaliação e responsabilidade, o que promove a valorização do trabalho profissional dos professores - uma tendência que vem ganhando espaço em diferentes países (Ibdem, p. 146).

Por último, o texto, sob a forma de anexo, analisa a situação dos cursos de formação de professores em nível médio, com base em dados obtidos junto a dezessete estados que atenderam a solicitação do Ministério da Educação (MEC) e enviaram suas propostas curriculares. O anexo do documento está organizado em itens: características gerais da habilitação magistério; perfil dos alunos; formas de elaboração das propostas; contradição entre discurso e encaminhamentos curriculares; componentes curriculares; duração e carga horária e organização curricular. É preciso salientar que a análise feita atribuiu à formação em nível médio, majoritária em território nacional naquela época, um status de desprestígio social, provocado contundentemente pelo perfil de seus alunos e pela desarticulação e fragilidade de sua proposta e organização curriculares.

Entre todos os aspectos abordados, dois ocupam centralidade nos Referenciais de 1999. São reforçados os discursos que conduzem a formação inicial pautada pelas competências, como forma de profissionalizar o docente e à introdução da meritocracia como política de valorização da carreira docente.

\section{As Diretrizes de 2002}

Iniciativas de regulação da profissão docente, bem como a apresentação de um novo perfil para a formação de professores da educação são delineadas a partir da definição das Diretrizes Nacionais para a Formação Inicial de Professores para a Educação Básica em Nível Superior, aprovadas pelo Conselho Nacional de Educação (CNE), em oito de maio de 2001 e homologadas em fevereiro de 2002 (Freitas, 2002): "Seu conteúdo aborda desde as competências e habilidades a serem desenvolvidas nos futuros professores, carga horária, passando pela questão da avaliação - de curso e de professores - até a organização institucional e pedagógica das instituições formadoras" (Ibdem, p. 150). 
Tanto no Parecer CNE/CP 009/2001 que constitui a Proposta das Diretrizes Curriculares Nacionais para a Formação de Professores da Educação Básica, como na Resolução CNE/CP N ${ }^{\circ} 1$, de 18 de Fevereiro de 2002 que institui as Diretrizes Curriculares Nacionais para a Formação de Professores da Educação Básica, em nivel superior, curso de licenciatura, de graduação plena, "a concepção de competência é nuclear na orientação do curso de formação de professores" (Brasil, 2001, p.28). É interessante perceber que, ao longo das suas setenta páginas, o Parecer CNE/CP 009/2001 faz referência ao termo competências por 69 vezes e a Resolução CNE/CP 001/02, faz uso do termo por 21 vezes, ao longo de suas cinco páginas.

De acordo com Freitas (2002), a incorporação da noção e do modelo de competências na definição do perfil do novo profissional para fazer face às exigências postas pela reforma educativa são introduzidas nas Diretrizes,

Através de orientações firmadas anteriormente no âmbito da comissão do MEC responsável pela elaboração do documento norteador das presentes diretrizes. Grande parte das elaborações teóricas, entretanto, já fazia parte de documento de Mello [...], no qual identificamos indícios da estreita vinculação entre as propostas para a formação de professores e as exigências postas pela reforma educativa da educação básica e pelos sistemas de avaliação em desenvolvimento (Ibdem, p. 153, 154).
No documento citado por Freitas (2002), intitulado Formação Inicial de Professores para a Educação Básica: uma (re)visão radical, publicado em 1999 e escrito por Guimar de Namo Mello (1999), uma das relatoras do Parecer que apresentou a proposta para as Diretrizes de 2002, encontramos os fundamentos inspiradores das propostas de formação apontadas pelas diretrizes:

Os professores não são necessários para qualquer projeto pedagógico, mas para aqueles que vão trabalhar de acordo com as diretrizes estabelecidas na lei, promovendo a constituição das competências definidas nas diferentes instâncias de normatização e recomendação legal e pedagógica, para ensinar e fazer aprender os conteúdos que melhor podem ancorar a constituição dessas competências. Os modelos de instituições de formação docente que interessam ao país são, portanto, aqueles que propiciam ou facilitam a construção de um perfil de profissional adequado para essa tarefa. (Mello, 1999, p.10, grifo nosso).

Segundo o Parecer CNE/CP 009/2001 serão as competências que orientarão "a seleção e o ordenamento de conteúdos dos diferentes âmbitos de conhecimento profissional bem como a alocação de tempos e espaços curriculares", operando como "diretrizes para a organização da matriz curricular" (Brasil, 2001, pp.5152). Além disso, a organização das escolas de formação deverá se colocar "a 
serviço do desenvolvimento de competências" (Ibdem, p.49). Ao esclarecer sobre a concepção, o desenvolvimento e a abrangência da formação de professores, o Parecer 001/02 ressalta:

Conceber e organizar um curso de formação de professores implica: a) definir o conjunto de competências necessárias à atuação profissional; b) tomá-las como norteadoras tanto da proposta pedagógica, em especial do currículo e da avaliação, quanto da organização institucional e da gestão da escola de formação (Ibdem, p.36).

Sendo assim, deverão também as competências, de acordo com as Diretrizes, servir de "referência para todas as formas de avaliação dos cursos", sendo tais avaliações:

I - periódicas e sistemáticas, com procedimentos e processos diversificados, incluindo conteúdos trabalhados, modelo de organização, desempenho do quadro de formadores e qualidade da vinculação com escolas de educação infantil, ensino fundamental e ensino médio, conforme o caso; II - feitas por procedimentos internos e externos, que permitam a identificação das diferentes dimensões daquilo que for avaliado; III - incidentes sobre processos e resultados (Brasil, 2002, (s.p.), grifo nosso).

Tão forte é a ênfase dada pelas Diretrizes às competências no curso de formação de professores, que elas também deverão estabelecer o mesmo padrão de avaliação centrado nas competências aos professores da educação básica, através da criação de um "sistema federativo de certificação” (Brasil, 2002, s.p.).

Tal ideia também fora defendida e recomendada por Mello (2000). Segundo a autora, um sistema nacional de certificação de competências para professores torna possível estabelecer "um padrão de qualidade nacional", que poderá impedir qualquer pessoa de ser professor, caso "seu desempenho revelar competências profissionais inferiores ao padrão nacional" (Ibdem, p.108).

Contrario ao documento, porém, alguns autores discutirão que a relação entre a formação do educador e os processos de avaliação, mas precisamente a avaliação das competências, traz para a discussão a certificação dessas competências.

O processo de certificação de competências contribuirá para aprofundar o quadro perverso caracterizado pela ausência de políticas de valorização e de formação continuada, pelas péssimas condições de funcionamento de grande maioria das escolas públicas e pela redução de recursos públicos para o aprimoramento do processo educativo, trazendo como consequências a culpabilização e responsabilização dos professores pelo sucesso e/ou fracasso da escola e da educação pública (Freitas, 2002, p.157).

De acordo com Ramos (2001), 
A competência passa a estar no princípio da organização do trabalho, no lugar da qualificação/profissão. Enquanto o domínio de uma profissão, uma vez adquirido, não pode ser questionado (no máximo pode ser desenvolvido), as competências são apresentadas como propriedades instáveis dentro e fora do exercício do trabalho. Significa dizer que uma gestão fundada na competência encerra a ideia de que um assalariado deve se submeter a uma validação permanente, dando constantemente provas de sua adequação ao posto, de seu direito a uma promoção ou a uma mobilidade promocional. (Ibdem, p. 194).

Como podemos ver, as temáticas da profissionalização do magistério e da formação docente aproximam-se, portanto, de forma bastante estreita, da temática da avaliação, através da incorporação das competências ao discurso oficial das novas políticas educacionais. A definição de diretrizes nacionais centradas em competências tem se complementado com o estabelecimento de sistemas de avaliação. Na ótica dos currículos centralizados, o currículo por competências torna-se necessário, tendo em vista a exigência da definição de desempenhos que demonstrem a sua aquisição, logo que possam ser avaliados. De acordo com Brzezinski (2007, p.235), referindo-se ao curso de Pedagogia, "as diretrizes visam a normatizar critérios comuns que sirvam de parâmetros ao Sistema Nacional de Educação para avaliar a qualidade da formação e acompanhar a trajetória de egressos".

Segundo Dias e Lopes (2003), o modelo curricular por competências busca a redefinição do processo de formação contínua dos professores em torno de sua profissionalização, pautada na concepção de competência profissional. A garantia do estabelecimento de um estatuto profissional da atividade docente está entre as razões mais destacadas para a adoção das competências como paradigma curricular (Ibdem, p. 1161).

As autoras criticam a proposta de currículo para formação de professores, sustentada pelo desenvolvimento de competências, pois ela "anuncia um modelo de profissionalização que possibilita um controle diferenciado da aprendizagem e do trabalho dos professores". Sendo assim, ressalta que "um dos mecanismos apontados pelos documentos oficiais para o controle da formação de professores é o processo de avaliação de competências" (Ibdem, p. 1158)

Ao analisar a estreita vinculação entre as competências e a avaliação que permeia as Diretrizes Curriculares Nacionais (DCN 2002), Freitas (2002) levanta pontos importantes. Segundo ela, tal vinculação ressalta a centralização da avaliação no âmbito do Ministério da Educação e do Instituto Nacional de Estudos e Pesquisas Educacionais Anísio Teixeira (INEP) e tem origem nas orientações do Banco Mundial visando 
à implementação da reforma educativa (Torres, 1998). Além disso,

Uma Agência Nacional de Avaliação teria como objetivo centralizar todos os processos de avaliação em todos os níveis de ensino, desde a avaliação dos conteúdos do ensino até a avaliação de docentes - de todos os professores - da educação básica à superior. Esta discussão da avaliação não se reduz, portanto, exclusivamente à avaliação institucional do aparato escolar, mas amplia-se para a avaliação dos sujeitos envolvidos no processo educativo - os alunos, os estudantes e os professores (Freitas, 2002, p. 157).

Assim, a avaliação das competências é tangenciada pela dimensão da certificação. Nas DCN, uma das propostas para a formação de professores foi a organização de um sistema federativo de certificação de competência dos professores de educação básica. Iniciativas como essas vão na direção de atender às necessidades postas pelo modelo de competências de submeter os trabalhadores/professores a uma validação permanente, como nos diz Ramos (2001), dando constantemente provas de sua adequação às necessidades do trabalho pedagógico.

\section{As Diretrizes para Pedagogia (2006)}

Na esteira do processo de formulação e regulação da formação de professores, localizado nos anos de 2005 e
2006, o CNE aprovou o Parecer CNE/ CP 05/2005, reexaminado pelo Parecer CNE/CP 03/2006, e a Resolução CNE/CP 01/2006, que definiram e instituíram as Diretrizes Curriculares Nacionais para o Curso de Graduação em Pedagogia, licenciatura. De acordo com a Resolução, sua aplicação visava, especificamente,

À formação inicial para o exercício da docência na Educação Infantil e nos anos iniciais do Ensino Fundamental, nos cursos de Ensino Médio na modalidade Normal e em cursos de Educação Profissional, na área de serviços e apoio escolar, bem como em outras áreas nas quais sejam previstos conhecimentos pedagógicos (Brasil, 2006, p.1).

A direção indicada pelas Diretrizes Curriculares Nacionais (DCN) do curso de Pedagogia é oposta em relação às propostas curriculares regulamentadas anteriormente, inclusive em relação às DCN dos demais cursos de formação de professores, tendo em vista serem resultado de contradições, debates e embates que engendraram o campo da formação de professores, ao longo da segunda metade dos anos 1990 e a primeira metade dos anos 2000, e antes disso, de toda a luta histórica empreendida nos anos 1980, conforme já considerado anteriormente. É possível notar, então, que

Enquanto as políticas educacionais deste período apontavam para uma formação docente de caráter mais pragmático, orientada pela pedago- 
gia das competências, desarticulada da pesquisa e da problematização teórica, especialmente no caso da formação dos profissionais para educação infantil e anos iniciais do ensino fundamental, pesquisadores e trabalhadores da educação reivindicavam e se mobilizavam no sentido de assegurar que esta formação se realizasse na universidade, enquanto instituição de ensino superior que deve articular ensino, pesquisa e extensão (Palafox et al., 2013, p. 320).

As DCN do curso de Pedagogia resultam, portanto, de uma ampla, longa e discutida reforma na organização dos cursos de graduação e na formação dos profissionais da educação no Brasil. Não é sem propósito, portanto, que sua regulamentação aconteça somente após quase uma década do início do processo de mudança curricular empreendido pela Secretaria de Ensino Superior do Ministério de Educação (Sesu/MEC), por meio do Edital $N^{\circ}$. 4, de 4 de dezembro de 1997 que solicitava às Instituições de Ensino Superior (IES)o envio de propostas para a elaboração das diretrizes curriculares para os cursos de graduação.

De acordo com Brzezinski (2007), foi instalada uma grande tensão no percurso de elaboração das DCN do curso de Pedagogia, inicialmente pelo encaminhamento do "Documento das Diretrizes Curriculares do Curso de Pedagogia" ao 64 Conselho Nacional de Educação (CNE), em 06/05/1999, pela Comissão de Espe- cialistas de Ensino de Pedagogia ${ }^{\top}$ (CEEP), composta por educadores vinculados à faculdades de educação de universidades brasileiras. O documento baseava-se nas sugestões enviadas pelas coordenações de cursos das Instituições de Ensino Superior e nas discussões empreendidas nacionalmente por entidades da área, particularmente a Associação Nacional pela Formação dos Profissionais da Educação (Anfope), apoiada em suas concepções centrais pela Associação Nacional de Pesquisa e Pós-Graduação em Educação (Anped), o Fórum de Diretores de Faculdades/Centros de Educação das Universidades Públicas Brasileiras (Forumdir), a Associação Nacional de Política e Administração da Educação (Anpae) e o Centro de Estudos Educação e Sociedade-Cedes (Scheibe, 2007) . A tensão residia no fato de que a Secretaria de Educação Superior (SESu/MEC) e a Secretaria de Ensino Fundamental (SEF/ MEC) resistiram terminantemente ao envio desse documento ao $\mathrm{CNE}$, tendo em vista que o grande interesse de tais secretarias era estabelecer diretrizes para o Curso Normal Superior, criado pela Lei No.9.394/1996. Era preciso ganhar

Esta Comissão foi nomeada pela Portaria SESu/MEC Nº.146 de 10 de março de 1998, e composta pelos professores: Celestino Alves da Silva (Universidade Estadual Paulista - Unesp/Marília); Leda Scheibe, presidenta (Universidade Federal de Santa Catarina UFSC); Márcia Ângela Aguiar (Universidade Federal de Pernambuco - UFPE), Tizuko Morchida Kishimoto (Universidade de São Paulo-USP) e Zélia Mileo Pavão (Pontifícia Universidade Católica - PUC/PR). 
tempo, enquanto aguardava-se a regulamentação do Curso Normal Superior.

No entanto, mediante mobilização e pelo esforço das entidades ${ }^{8}$, a proposta chegou ao Conselho Nacional acompanhada de um conjunto de assinaturas que solicitava sua apreciação. Mesmo assim, não foi encaminhada para efetiva discussão e deliberação.

Após seis anos de expectativa, finalmente, em 17 de março de 2005, o silêncio do CNE foi rompido com a divulgação, via eletrônica, de uma minuta de Diretrizes Curriculares Nacionais para os Cursos de Graduação em Pedagogia, para apreciação da sociedade civil. Tal minuta foi amplamente rejeitada pela comunidade acadêmica, por encaminhar, para o curso de Pedagogia, diretrizes claramente identificadas com o Curso Normal Superior.

Muitos manifestos de indignação à minuta de diretrizes foram produzidos. Brzeznski (2007, p. 242) ressalta que as principais considerações dos manifestos pautavam-se na "ruptura do CNE com as proposições encaminhadas por diversas associações e entidades representativas dos profissionais da educação, no período 1999-2004", em franca descon-

$8 \quad$ Em 07 de novembro de 2001, as entidades entregaram ao CNE o documento "Posicionamento Conjunto das Entidades", reafirmando as diretrizes curriculares para o curso de Pedagogia de 1999 e fortalecendo o conjunto de proposituras das entidades no Movimento Nacional de Educadores. Tal documento foi redigido na Faculdade de Educação da Universidade Federal Fluminense. sideração às "experiências curriculares do curso de Pedagogia desenvolvidas com êxito pelas universidades em todo território nacional"; a "nítida dissociação entre licenciatura e bacharelado em Pedagogia" contida na proposta da minuta do CNE; a "contradições em relação à formação do profissional licenciado em "habilitações" fragmentadas (Art.. $2^{\circ}$ ) e o perfil centrado em "competências" no anseio de "produzir um super pedagogo".

Os educadores manifestam sua estranheza ao desprezo do CNE, especialmente, para com as duas teses defendidas por aqueles que formam pedagogos e vivenciam cotidianamente essa realidade, quais sejam: A base do Curso de Pedagogia é a docênciae (...) O Curso de Pedagogia é ao mesmo tempo uma licenciatura e um bacharelado (Manifesto de Goiás, 2005, p. 1, 2 apud Brzezinski, 2007, p.242).

Em documento conjunto da Anfope, Anped, Cedes, Forumdir, enviado ao CNE, em abril de 2005 e, também baseado no Manifesto de Goiás, o Movimento Nacional de Educadores contrapunha-se às contradições e equívocos que atravessavam a minuta de DCN para o curso de Pedagogia, enfatizando que

A luta pela formação do educador de caráter socio-histórico e a concepção da docência como base da formação dos profissionais da educação - não se confunde com a redução do Curso de Pedagogia a uma licenciatura e têm outro caráter: indicam a necessidade 
de superação tanto da fragmentação na formação - não separando a formação do professor da formação dos especialistas - quanto para a superação da dicotomia entre formação do licenciado e do bacharel - construindo a concepção de formação do professor e do especialista no educador (grifos dos autores) (Anfope et al., 2005, p.2 apud Brzezinski, 2007, p.243).

O processo de mobilização nacional em prol de diretrizes que contemplassem as propostas construídas historicamente pelo movimento dos educadores não foi em vão. A partir dele, foi elaborado pelo CNE novo Parecer (05/2005) sobre as diretrizes curriculares nacionais para 0 Curso de Pedagogia, aprovado em reunião do Conselho Pleno do Conselho Nacional de Educação em 13 de dezembro de 2005, com a presença de representantes da Anfope, Cedes e Forundir.

A partir de uma "solução negociada", segundo Brzezinski (2007, p.244), foram instituídas em 2006, através da Resolução CNE/CP, No 1 , de 15 de maio de 2006, as Diretrizes Curriculares Nacionais para o Curso de Graduação em Pedagogia, licenciatura. Entre consensos e dissensos, estão presentes no Parecer elementos que constituem a luta empreendida pela formação dos profissionais da educação ao longo de vários anos. Dentre eles, podemos destacar a confirmação da 66 docência como a base da identidade do pedagogo (Art. $2^{\circ}$ ); a explicitação da concepção de docência (Art. $2^{\circ}, \S 1^{\circ}$ ) que contemplam os aspectos concebidos por Freire (1997), a saber, "compreensão da realidade, diálogo, reflexão sobre a prática, pesquisa, curiosidade, tolerância, alegria, ética e estética, humildade e mais, a convicção de que a mudança é possível" (Ibdem, p. 245); a formação do pedagogo perspectivada em diferentes dimensões e não apenas na docência da educação infantil e do ensino fundamental (Art. $4^{\circ}$ ); a eliminação das habilitações, (Art. $10^{\circ}$ ); garantia da organização curricular baseada em núcleos de estudos (Art. $6^{\circ}$ ).

É importante ressaltar, no entanto, que o parecer não se refere à formação do pedagogo, mas à formação do licenciado em pedagogia, em franca oposição à luta das principais entidades que defendem, como anteriormente considerado, que "o curso de Pedagogia porque forma o profissional de educação para atuar no ensino, na organização e gestão de sistemas, unidades e projetos educacionais e na produção e difusão do conhecimento, em diversas áreas da educação, é, ao mesmo tempo, uma Licenciatura e um Bacharelado (Anfope, et al., 2005).

No entanto, é impossível não admitir que, a partir de todos os movimentos de luta e resistência, o discurso que se desenvolvia desde os anos 1990 e esteve presente nos documentos curriculares desde então perde hegemonia e outros discursos circulantes se tornam potentes.

\section{As Diretrizes de 2015}

As novas diretrizes curriculares nacionais para a formação inicial e continuada dos 
profissionais do magistério da educação básica, homologadas pelo Ministério da Educação (MEC) em 24 de junho de 2015, foram objeto de discussões e debates por mais de uma década no Conselho Nacional de Educação (Dourado, 2015). Além de objetivarem garantir maior organicidade à formação inicial dos profissionais para o magistério da educação básica, também tencionam abranger a formação continuada desses profissionais.

Apesar de materializar concepções historicamente defendidas por entidades da área, especialmente Anfope, Anpae, Anped, Cedes e Forumdir, em grande medida, as Diretrizes também são resultantes das deliberações das Conferências Nacionais de Educação (Conae, 2010 e 2014) que desempenharam papel importante.

9 A Conferência Nacional de Educação (Conae) é um espaço democrático aberto pelo Poder Público e articulado com a sociedade para que todos possam participar do desenvolvimento da Educação Nacional. Convocada pela Portaria No 1.410 , de 03 de dezembro de 2012, a Conae/2014 teve caráter deliberativo e objetivou apresentar um conjunto de propostas para subsidiar a implementação do Plano Nacional de Educação (PNE), indicando responsabilidades, corresponsabilidades, atribuições concorrentes, complementares e colaborativas entre os entes federados e os sistemas de ensino. As conferências nacionais de educação são coordenadas pelo Fórum Nacional de Educação (FNE), conforme estabelece a Portaria MEC No 1407, de 14 de dezembro de 2010.
Ao destacar a articulação entre Sistema Nacional de Educação, as políticas e a valorização dos profissionais da educação, bem como ao reafirmar uma base comum nacional para a formação inicial e continuada cujos princípios devem ser considerados na formulação dos projetos institucionais de formação inicial e continuada - incluindo a licenciatura - por meio da garantia de concepção de formação pautada tanto pelo desenvolvimento de sólida formação teórica e interdisciplinar em educação de crianças, adolescentes, jovens e adultos(as) e nas áreas específicas de conhecimento científico quanto pela unidade entre teoria e prática e pela centralidade do trabalho como princípio educativo na formação profissional, como também pelo entendimento de que a pesquisa se constitui em princípio cognitivo e formativo e, portanto, eixo nucleador dessa formação (Dourado, 2015, p.301).

Além disso, todas as metas e estratégias do Plano Nacional de Educação, aprovado pela Lei 13005 de 25 de junho de 2014, que incidem nas bases para a efetivação de uma política nacional de formação dos profissionais da educação, em especial as metas 12, 15, 16, 17 e 18 , e suas respectivas estratégias, foram consideradas nas diretrizes curriculares nacionais para a formação inicial e continuada dos profissionais do magistério.

As Diretrizes (Brasil, 2015), ao considerarem concepções fundamentais para a melhoria da formação inicial e conti- 
nuada, reforçam que as instituições de educação básica, seus processos de organização e gestão e projetos pedagógicos cumprem, sob a legislação vigente, um papel estratégico na formação requerida nas diferentes etapas (educação infantil, ensino fundamental e ensino médio) e modalidades da educação básica e assinalam para a "necessidade de articular as Diretrizes Curriculares Nacionais para a Formação Inicial e Continuada, em Nível Superior e as Diretrizes Curriculares Nacionais para a Educação Básica" (Ibdem, p.2).

Além disso, delineiam

Os princípios que norteiam a base comum nacional para a formação inicial e continuada, tais como: a) sólida formação teórica e interdisciplinar; b) unidade teoria-prática; c) trabalho coletivo e interdisciplinar; d) compromisso social e valorização do profissional da educação; e) gestão democrática; f) avaliação e regulação dos cursos de formação (Ibdem).

A garantia de base comum nacional, sem prejuízo de base diversificada, pautada pela concepção de educação como processo emancipatório e permanente, bem como pelo reconhecimento da especificidade do trabalho docente, que conduz à práxis como expressão da articulação entre teoria e prática, e a exigência de que se leve em conta a realidade dos ambientes das instituições educativas da educação básica e da profissão constituem-se como pontos altos do documento.
As novas DCN também atentam para "a importância do profissional do magistério e de sua valorização profissional, assegurada pela garantia de formação inicial e continuada, plano de carreira, salário e condições dignas de trabalho" (Ibdem). Definem os princípios para a formação inicial e continuada de profissionais do magistério da educação básica, incluindo a educação escolar indígena, a educação escolar do campo e a educação escolar quilombola ${ }^{10}$, e apontam para a necessidade de maior articulação entre as instituições de ensino superior e de educação básica, envolvendo a consolidação de fóruns estaduais e distrital permanentes de apoio à formação docente, em regime de colaboração.

Esclarecem, no Art. 16, que a formação continuada compreende:

Dimensões coletivas, organizacionais e profissionais, bem como o repensar do processo pedagógico, dos saberes e valores, e envolve atividades de extensão, grupos de estudos, reuniões pedagógicas, cursos, programas e ações para além da formação mínima exigida ao exercício do magistério na educação básica, tendo como principal finalidade a reflexão sobre a prática educacional e a busca de aperfeiçoamento técnico, pedagógico, ético e político do profissional docente (Brasil, 2015, p.13).

\footnotetext{
10 Membro de comunidade remanescente dos quilombos, que abrigavam escravos negros fugidos.
} 
Ressaltando a importância dos estados e municípios, assim como as instituições educativas de educação básica no oferecimento da formação continuada, "as novas DCN reconhecem esse lócus de formação continuada como parte constitutiva da nova política que se quer consolidar no país" (Dourado, 2015, p.307).

No que tange à formação inicial, o documento define que os cursos de formação inicial para os profissionais do magistério para a educação básica, em nível superior, compreendem: I. Cursos de graduação de licenciatura; II. Cursos de formação pedagógica para graduados não licenciados; III. Cursos de segunda licenciatura. Para tanto, a instituição formadora deverá adequar seu projeto institucional de formação com vistas a contemplar a formação do profissional do magistério da educação básica, para o exercício da docência e da gestão educacional e escolar na educação básica, o que vai requerer que essa formação em nível superior esteja adequada à área de conhecimento e às etapas e modalidades de atuação e que possibilite acesso a conhecimentos específicos sobre gestão educacional e escolar, bem como formação pedagógica para o exercício da gestão e coordenação pedagógica e atividades afins. A formação inicial de profissionais do magistério deverá ser ofertada, preferencialmente, de forma presencial, com elevado padrão acadêmico, científico e tecnológico e cultural.

No que diz respeito à constituição dos cursos de formação inicial, fica definido que serão organizados a partir de três núcleos:

I. Núcleo de estudos de formação geral, das áreas específicas e interdisciplinares, e do campo educacional, seus fundamentos e metodologias, e das diversas realidades educacionais; II. Núcleo de aprofundamento e diversificação de estudos das áreas de atuação profissional, incluindo os conteúdos específicos e pedagógicos e as persquizas priorizadas pelo projeto pedagógico das instituições, em sintonia com os sistemas de ensino; e III. Núcleo de estudos integradores para enriquecimento curricular. (Ibdem, p. 309).

Tal organização reflete a trajetória das instituições formadoras, com especial destaque ao movimento empreendido pela Comissão Nacional de Reformulação dos Cursos de Formação do Educador (Conarcfe)/Anfope, nos anos 1980 e 1990 ao propor eixos curriculares "como espaços coletivos de discussão e ação que atravessariam cada disciplina do currículo, viabilizando propostas coletivas", em franca rejeição à ideia de um currículo mínimo e pela defesa da base comum nacional, conforme já abordado anteriormente.

As novas DCN também definem a estrutura e o currículo dos cursos de formação inicial. Os cursos deverão ter,

No mínimo, 3.200 (três mil e duzentas) horas de efetivo trabalho acadêmico, em cursos com duração de, no mínimo, 8 (oito) semestres ou 4 (qua- 
tro) anos, compreendendo: I - 400 (quatrocentas) horas de prática como componente curricular, distribuídas ao longo do processo formativo; II 400 (quatrocentas) horas dedicadas ao estágio supervisionado, na área de formação e atuação na educação básica, contemplando também outras áreas específicas, se for o caso, conforme o projeto de curso da instituição; III - pelo menos 2.200 (duas mil e duzentas) horas dedicadas às atividades formativas estruturadas pelos núcleos definidos nos incisos I e II do Artigo 12 desta Resolução, conforme o projeto de curso da instituição; IV - 200 (duzentas) horas de atividades teórico-práticas de aprofundamento em áreas específicas de interesse dos estudantes, conforme núcleo definido no inciso III do artigo 12 desta Resolução, por meio da iniciação científica, da iniciação à docência, da extensão e da monitoria, entre outras, consoante o projeto de curso da instituição (Brasil, 2015, s.p., Grifo dos autores).

É importante destacar que a identidade do profissional do magistério perseguida pelas DCN está associada à necessidade de articulação constante entre teoria e prática, não isolando tal relação ao estágio supervisionado, mas contemplando sua efetivação nos demais componentes curriculares. Também preveem cursos de formação pedagógica para graduados

70 não licenciados e cursos de segunda licenciatura, ambos com carga horária específica, de acordo com critérios pró- prios. Ressaltam que a "valorização do magistério e dos demais profissionais da educação deve ser entendida como uma dimensão constitutiva e constituinte de sua formação inicial e continuada", dentre alguns aspectos, a garantia de planos de carreira e salário, condições de jornada de trabalho, formas de acesso e provimento ao cargo, progressão na carreira, avaliação de desempenho com a participação dos pares, adequada relação professor/educando.

\section{As Diretrizes de 2015 e os movimentos de educadores: as comunidades epistêmicas trazendo e empoderando novos discursos sobre formação docente}

De fato, torna-se nítido que as novas DCN pretendem materializar os movimentos de luta e reivindicações dos profissionais do magistério brasileiro nas últimas décadas. Nas novas DCN o discurso que legitima as competências como central na formação de professores desaparece. A tônica do discurso gira em torno da afirmação de uma base comum nacional para a formação inicial e continuada e na articulação entre Sistema Nacional de Educação, as políticas e a valorização dos profissionais da educação. Tal discurso, antes praticamente invisível, agora torna-se hegemônico, pelo menos na legislação.

No caso específico das políticas de currículo, Lopes (2006) defende que os discursos hegemônicos são disseminados 
por comunidades epistêmicas com capacidade de influência nos Estados-Nação, muitas vezes atravessando diferentes sociedades políticas.

As comunidades epistêmicas são compostas por grupos de especialistas que compartilham concepções, valores e regimes de verdade comuns entre si e que operam nas políticas pela posição que ocupam frente ao conhecimento, em relações de saber-poder. O que distingue as comunidades epistêmicas de outros agentes sociais atuantes nas políticas é o fato de serem constituídas por uma rede de profissionais com competência reconhecida em um domínio de conhecimento particular, ao mesmo tempo que reivindicam uma autoridade política relevante em função desse conhecimento que dominam (Ibdem, p. 40, 41).

As comunidades epistêmicas que atuam nas políticas de currículo podem ser compostas por atores do campo educacional, das áreas de ensino de disciplinas específicas ou do campo da economia e da administração, e se utilizam de instrumentos de homogeneização (Appadurai, 2001 apud Lopes, 2006), na medida em que fazem circular diagnósticos por elas desenvolvidos sobre a situação educacional e organizam modelos de solução para os problemas identificados, valorizando seu próprio conhecimento como fonte dessas soluções. Ball utiliza o conceito de comunidade epistêmica ao abordar o contexto de influência a partir da circulação de ideias a respeito da educação e de suas políticas por diferentes sujeitos e grupos sociais (Dias; López, 2003). Assim, "o modo de influenciar seria via organismos internacionais ou mesmo pela disseminação das ideias de teóricos sobre as experiências dos países, com o propósito de apoiá-las e difundi-las, internacionalmente, via publicações, palestras, consultorias, etc" (Ibdem, p.57).

Porém, tendo em vista que as comunidades epistêmicas assumem dinâmicas globais e locais, é possível perceber que estas também se articulam com as comunidades disciplinares. Segundo Lopes (2006, p.41), "muitas vezes os especialistas atuantes nas políticas de currículo são membros de comunidades disciplinares, seja da pedagogia ou das comunidades de ensino de disciplinas específicas ou ainda das comunidades das ciências de referência".

No caso das novas DCN é possível dizer que a existência de membros do Conselho Nacional de Educação, atuantes nas principais entidades em defesa da formação de professores no Brasil, foi de fundamental importância para a hegemoneização de certos discursos, em destaque, entre poucos outros, seu relator, o professor Luís Fernandes Dourado $^{11}$, e as professoras Malvina Tania

11 Professor Titular e Emérito da Universidade Federal de Goiás. Entre 2012-2016 foi Membro da Câmara de Educação Superior do Conselho Nacional de Educação, entre 2014/2016 foi membro do Fórum Nacional de Educação. Foi Diretor da Secretaria de 
Tuttman ${ }^{12}$ e Márcia Angela da Silva Aguiar ${ }^{13}$, agentes atuantes dos principais movimentos em defesa da formação de professores.

De acordo com Dias, os processos de articulação comuns nos contextos de definição de textos políticos, possibilitam a incorporação de diferentes proposições,

Criam novos sentidos sobre a formação de professores e fortalecem outros, em busca da legitimidade

Educação Básica do MEC, Coordenador Geral de Estatísticas Especiais do INEP, Secretário Adjunto da ANPEd e Diretor de Pesquisa da ANPAE. Entre 2007-2014 foi Editor da Revista Retratos da Escola/CNTE/ Esforce (2007/2014).

12 Há 35 anos é professora da Universidade Federal do Estado do Rio de Janeiro (UNIRIO), instituição da qual foi Diretora da Escola de Educação, Pró-Reitora de Extensão e Reitora de 2004 a 2011. De 2011 a 2012, assumiu a Presidência do Instituto Nacional de Estudos e Pesquisas Educacionais Anísio Teixeira (INEP). No ano de 2012, passou a ser membro do Conselho Nacional de Educação - CNE, da Câmara de Educação Básica, e membro do Conselho Estadual de Educação do Estado do Rio de Janeiro - CEE/RJ.

13 Professora Titular do Centro de Educação e do Programa de Pós-Graduação em Educação da Universidade Federal de Pernambuco. Foi a primeira coordenadora da Comissão Nacional dos Cursos de Formação do Educador, presidente da Associação Nacional para a Formação dos Profissionais da Educação (Anfope), coordenadora do GT-Estado e Política Educacional, vice-presidente e presidente da Associação Nacional de Pesquisa e Pós-Graduação em Educação (ANPEd). Atualmente atua como Membro na Câmara de Educação Superior do Conselho Nacional de Educação. da política para a formação docente no Brasil. Nesses processos, representantes do Estado e membros da comunidade epistêmica da formação de professores, participam de várias formas com a finalidade de influenciar as decisões sobre essa política. As diferentes influências que caracterizam o processo de produção de políticas criam uma tensão, possibilitando desse modo a fixação parcial dos sentidos que determinada política expressa em seus textos de definição, levando em conta os múltiplos contextos em que a política é engendrada (Dias, 2012, p.5).

Nesse sentido, é preciso entender que a produção das políticas públicas curriculares provoca um processo de articulação de demandas que são disputadas tendo como finalidade a construção de um projeto que busca hegemonia. Em torno dessas lutas por um projeto de formação de professores, sempre são produzidas diferentes propostas que se consolidam em definições curriculares que orientam cursos de formação e influenciam outras propostas para as políticas de formação docente. Nessa luta por significação das políticas, alguns sentidos são privilegiados no processo de definição de políticas, e outros não (Dias, 2012).

\section{Referências Bibliográficas}

Anfope; Anped; Anpae; Cedes \& Forundir (2005). Documento das entidades sobre a Resolução do CNE. Brasília. Recuperado 
Políticas curriculares e formação de professores no Brasil: a disputa em torno do conceito de competências

em http://www.scielo.br/pdf/es/v26n90/ a01v2690.pdf

Ball, S. (1994). Educational reform: a critical and post-structural approach. Buckingham, Inglaterra: Open University Press.

(2001). Diretrizes políticas globais e relações políticas locais em educação. Currículosemfronteiras, 1(2), pp. 99-116 Recuperado em http://www.curriculosemfronteiras.org/volliss2articles/ ball.pdf

Brasil (1996). Lei No 9394/96, de 20 de dezembro de 1996. Estabelece as diretrizes e bases da educação nacional. Diário Oficial da União, Brasília, DF, Recuperado em http://www.planalto.gov.br/ccivil_03/ leis/19394.htm.

(1999). Decreto No3.276, de 6 de dezembrode 1999. Dispõe sobre aformação em nível superior de professores paraatuar naeducação básica, e dá outras providências. Presidência da República Casa Civil Subchefia para Assuntos Jurídicos. Brasilia. Recuperado em, de http://www. planalto.gov.br/ccivil_03/decreto/ D3276.htm

(2015). Parecer CNE/CP N 2/2015.

Diretrizes Curriculares Nacionais para a Formação Inicial e Continuada dos Profissionais do Magistério da Educação Básica. Brasília: CNE/CP. Recuperado em: http://pronacampo.mec.gov.br/images/ pdf/res_cne_cp_02_03072015.pdf

(2015). Resolução $n^{\circ} 2$, de $1^{o}$ de julho de 2015. Define as Diretrizes Curriculares Nacionais para a formação inicial em nível superior (cursos de licenciatura, cursos de formação pedagógica para graduados e cursos de segunda licenciatura) e para a formação continuada. Brasília: MEC/CNE/CP.
(2002). Resolução CNE/CPN $N^{\circ}$, de 18 de Fevereiro de 2002. Institui Diretrizes Curriculares Nacionais para a Formação de Professores da Educação Básica, em nível superior, curso de licenciatura, de graduação plena. Brasília: MEC/ CP.

(2006). Resolução CNE/CP No 1, de 15 de maio de 2006. Institui Diretrizes Curriculares Nacionais para o Curso de Graduação em Pedagogia, licenciatura. Brasília: MEC/CP.

(2014). Lein ${ }^{\circ} 13.005$, de 25 de junho de 2014. Aprova o Plano Nacional de Educação - PNE e dá outras providências. Brasília: Presidência da República.

Brzezinski, I. (Maio, 2007). Formação de professores para a educação básica e o Curso de Pedagogia: a tensão entre instituído e instituinte. RBPAE, 23(2), pp. 229-251.

Dias, R. E. (Agosto, 2012). Política curricular de formação de professores - um campo de disputas. Revista e-curriculum, 8,(2).

Dias, R. E., Lopes, A. C. (2003). Competências na formação de professores no Brasil: o que (não) há de novo. Educação E Sociedade, 24(85), p.10.

Dourado, L. F. (abr/jun, 2015). Diretrizes Nacionais Curriculares Nacionais para a formação inicial e continuada dos profissionais do magistério da educação básica: concepções e desafios. Educação E Sociedade, 36(131), pp. 299-324,

Freire, P. (1997). Educação e mudança. 21ª ed. São Paulo, Brasil: Paz e Terra.

Freitas, H. de (agosto, 2002). Formação de Professores no Brasil: 10 anos de embate entre projetos de formação. Educação $\varepsilon$ Sociedade, 23(80). 
(Jul/Dez, 2006). Discursos nas políticas de currículo. Currículosem Fronteiras, 6(2), pp.33-52,

Lopes, A. C., Macedo, E. (2011). Teorias de Currículo. São Paulo, Brasil: Cortez.

Lopes, A. C. (Jul/Dez, 2006). Discursos nas políticas de currículo. Currículo sem Fronteiras, 6(2), pp.33-52,

Mello, G. N. (1999). Formação inicial de professores para a educação básica: uma revisão radical. (Documento principal - versão preliminar para discussão interna. Mimeo.).

Mello, G. (2000) Formação inicial de professores para a educação básica: uma (re) visão radical. São Paulo em Perspectiva, 14(1), pp.98-110.

Palafox,H.., Klinke, K. \& da Silva, M., (mai/ ago,2013). Políticas de currículo, formação e valorização dos profissionais da educação pós-Constituição de 1988: um breve balanço. RBPAE, 29(2), pp. 305-325.

Ramos, M. (mai./ago, 2001). A pedagogia das competências. São Paulo, Brasil: Cortez.

Scheibe, L. (2007). Diretrizes curriculares para o curso de Pedagogia: uma solução negociada. RBPAE, 23(2), pp. 277-292.

Torres, R. M. (1998). Melhorar a qualidade da educação básica? As estratégias do Banco Mundial. In: Tommasi, L. de; Warde, M. J. \& Haddad, S. (orgs.). O Banco Mundial e as políticas educacionais. São Paulo, Brasil: Cortez. 